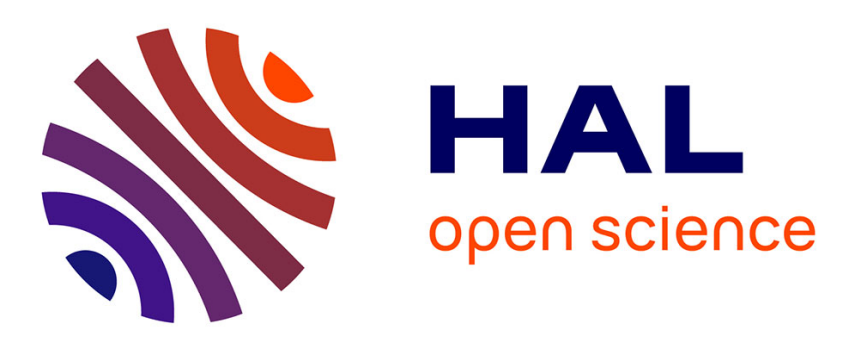

\title{
Evaluation of chiral ionic liquids as additives to cyclodextrins for enantiomeric separations by capillary electrophoresis
}

Yannis François, Anne Varenne, Emilie Juillerat, Didier Villemin, Pierre Gareil

\section{To cite this version:}

Yannis François, Anne Varenne, Emilie Juillerat, Didier Villemin, Pierre Gareil. Evaluation of chiral ionic liquids as additives to cyclodextrins for enantiomeric separations by capillary electrophoresis. Journal of Chromatography A, 2007, 1155 (2), pp.134-141. 10.1016/j.chroma.2006.12.076 . hal02988932

\section{HAL Id: hal-02988932 \\ https://hal.science/hal-02988932}

Submitted on 4 Nov 2020

HAL is a multi-disciplinary open access archive for the deposit and dissemination of scientific research documents, whether they are published or not. The documents may come from teaching and research institutions in France or abroad, or from public or private research centers.
L'archive ouverte pluridisciplinaire HAL, est destinée au dépôt et à la diffusion de documents scientifiques de niveau recherche, publiés ou non, émanant des établissements d'enseignement et de recherche français ou étrangers, des laboratoires publics ou privés. 
4 Yannis François ${ }^{1}$, Anne Varenne ${ }^{1}$, Emilie Juillerat ${ }^{1}$, Didier Villemin ${ }^{2}$, Pierre Gareil ${ }^{1 *}$

$7 \quad{ }^{1}$ Laboratory of Electrochemistry and Analytical Chemistry, UMR CNRS 7575, ENSCP, 11 rue 8 Pierre et Marie Curie, 75231 Paris cedex 05, France

$9{ }^{2}$ Laboratory of Molecular and Thio-organic Chemistry, UMR CNRS 6507, ENSI Caen, 6,

10 Boulevard du Maréchal Juin, 14050 Caen cedex, France

13 Running title: Chiral ionic liquids as chiral selectors for CE

15 Keywords: ionic liquids, capillary electrophoresis, chiral separations, choline-based ionic liquids, 16 neutral cyclodextrins, arylpropionic acids.

$19 *$ To whom correspondence should be addressed.

20 E-mail: pierre-gareil@enscp.fr. Tel : 331554263 71. Fax: 33144276750 


\section{Abstract}

26 A great interest has been drawn these last years towards ionic liquids in analytical chemistry, 27 especially for separation methods. Recent synthesis of chiral ILs opened the way of the 28 evaluation of new potential selectors for enantiomeric separations. This work focused on the

29 evaluation of two chiral ILs (ethyl- and phenylcholine of bis(trifluoromethylsulfonyl)imide) by 30 CE. Particular selectivities are awaited by exploiting unique ion-ion or ion-dipole interactions 31 and by tailoring the nature of the cation and the anion. To evaluate such phenomena, a study was 32 carried out with anti-inflammatory drugs 2-arylpropionic acids as model compounds. The results 33 show that these chiral ILs did not present direct enantioselectivity with regard to these model 34 analytes. The influence of chiral ILs in the electrolytes was then studied in the presence of 35 classical chiral selectors (di- or trimethyl- $\beta$-cyclodextrin). Although no general trend could be 36 established, an increase in separation selectivity and resolution was observed in some cases, 37 suggesting synergistic effects. The complementary determination of apparent inclusion constant 38 values of these IL cations in the used cyclodextrins by affinity CE provided support to the 39 understanding of the phenomena involved. 


\section{Introduction}

42
The high proportion of chiral compounds of biological or pharmacological interest has aroused a considerable need for the determination of the enantiomeric purities in the last twenty years. Since the pioneering works by Zare et al. [1] and Fanali et al. [2] and as testified by the very important amount of literature and a number of comprehensive reviews [3-11], capillary electrophoresis (CE) has proven to be an excellent alternative to classical chromatographic techniques in this field. The use in very small quantity and in free form of the chiral selector makes it possible to compare the effects of various selectors and afterwards perform routine analyses at lower cost.

A great interest is being triggered by ionic liquids (IL) as alternatives for conventional molecular solvents used in organic synthesis and catalytic reactions [12]. They supplement the family of "green solvents" including water and supercritical fluids. Among these, room temperature ionic liquids are defined as materials containing only ionic species and having a melting point lower than $298 \mathrm{~K}$. They exhibit many interesting properties such as negligible vapor pressure, low melting point, large liquid range, unique solvation ability and overall, the versatility of their physico-chemical properties makes them really attractive. They have been proposed as solvents for chemical reactions [13-15], multiphase bioprocess operations [16] and liquid-liquid separations [17,18], as electrolytes for batteries and fuel cells [19], stationary phases in gas chromatography [20-23] and mobile phase additives in liquid chromatography [24-26].

During these last years, a great attention has been paid to the relevance of these new media for capillary electrophoresis (CE) [27-37] and many efforts have been directed toward the understanding of the separation mechanisms involved in IL-containing background electrolytes (BGE). Concerning chiral separations, two applications only have been reported so far. The first one was with achiral ILs [38], 1-ethyl- and 1-butyl-3-methylimidazolium cations, associated with $\mathrm{BF}_{4}^{-}$or $\mathrm{PF}_{6}^{-}$anions. The enantioselectivity for binaphtyl derivatives was produced by a polymeric surfactant, whereas the presence of the ILs only modified the retention times and peak efficiency. Nevertheless, little was elucidated about the separation mechanism. Recent synthesis of chiral ILs $[39,40]$ opened the way of the evaluation of new potential selectors for enantiomeric separations. Rizvi et al. [41] realized the first chiral separation of several anionic compounds by micellar 
71 electrokinetic chromatography using two new synthetic chiral ionic liquids, undecenoxycarbonyl-

72 L-pryrrolidinol bromide and undecenoxycarbonyl-L-leucinol bromide.

73 This work was focused on the separation performances of two chiral ILs (ethyl- and

74 phenylcholine of bis(trifluoromethylsulfonyl)imide) by CE. In a previous work, a nonaqueous 75 capillary electrophoresis (NACE) study on the electrophoretic behavior of 2-arylpropionic acids 76 (profens), which were often selected as model chiral anionic compounds [42] in the presence of 77 an achiral imidazolium-based IL evidenced peculiar ion-pairing interactions between these 78 analytes and the achiral IL [43]. In the present work, the electrophoretic behavior of the same 79 model analytes was first studied in the presence of one of both chiral choline-based ILs in 80 nonaqueous media. As these chiral ILs alone did not present any enantioselectivity with regard to 81 these model analytes under the conditions tested, the influence of the chiral ILs was then studied 82 in aqueous and hydro-organic electrolytes containing classical chiral cyclodextrin selectors (di- or 83 trimethyl- $\beta$-cyclodextrin). The figures of merit (effective enantioselectivity and resolution) of the 84 chiral separations of the six arylpropionic acids were systematically determined, depending on 85 the nature and the concentration of the chiral IL and cyclodextrin, ionic strength and hydro86 organic composition of the electrolyte, to investigate for possible synergistic effects between the 87 two chiral selectors. In addition to this study, apparent inclusion constant values for the used 88 chiral ILs cations and neutral cyclodextrin derivatives were determined by affinity CE to provide 89 support to the understanding of phenomena involved. 


\section{2. Experimental}

92

\subsection{Chemicals and reagents}

94 Lithium bis(trifluoromethylsulfonyl)imide $\left(\operatorname{LiNTf}_{2}\right)(\geq 99 \%)$ was a gift from Institut Français du 95 Pétrole (Solaize, France). (R)(-) 2-hydroxy-N,N,N-trimethyl-1-phenylethanaminium (PhChol $96 \mathrm{NTf}_{2}$ ) and (R)(-) 1-hydroxy-N,N,N-trimethylbutan-2-aminium bis(trifluoromethylsulfonyl)imide 97 (EtChol $\left.\mathrm{NTf}_{2}\right)$ were synthesized (see section 2.2.) in Villemin's group (Caen, France). Methanol 98 (GC grade, 99.9\% purity) and sodium acetate were purchased from Prolabo (Fontenay-sous-Bois, 99 France). Formamide (> 99\%) and hexadimethrin bromide (Polybrene) were supplied by Aldrich

100 (St. Louis, MO, USA). Glacial acetic acid (> 99\%), Heptakis-(2,6-di-O-methyl)- $\beta$-cyclodextrin 101 (DM- $\beta$-CD) (> 90\%) and heptakis-(2,3,6-tri-O-methyl)- $\beta$-cyclodextrin (TM- $\beta$-CD) (> 90\%) were 102 obtained from Sigma (St. Louis, MO, USA). 2-arylpropionic acids (carprofen, suprofen, 103 naproxen, ketoprofen, indoprofen and ibuprofen) were donated by Rhone-Poulenc-Rorer (Vitry104 sur-Seine, France).

\subsection{Synthesis of chiral ionic liquids}

107 Wasserscheid et al have been the first to propose the use of choline derivatives as chiral ionic 108 liquid [44]. These chiral ammonium ions can be easily obtained from pure enantiomeric 109 aminoalcohol coming from the "chiral pool" as starting product.

110 The synthese of the chiral ionic liquids were achieved in two steps: (i) permethylation of amine 111 group into ammonium group and (ii) the metathesis exchange of anion.

112 In a typical procedure of permethylation, the $\mathrm{R}(-)$ 2-aminobutan-1-ol (0.44 $\mathrm{g}, 5 \mathrm{mmol})$ 113 [respectively, $\mathrm{R}(-)$ or $\mathrm{S}(+)$ phenylglycin-1-ol $(0.5 \mathrm{~g}, 3.6 \mathrm{mmol})]$ and the iodomethane $(2.13 \mathrm{~g}, 15$ $114 \mathrm{mmol})$ were refluxed in diethyl ether $(30 \mathrm{ml})$ under argon atmosphere and was protected from the 115 light. After six days'reflux, the solvent was removed by distillation under reduced pressure. The 116 reactional mixture was solubilized in water $(6 \mathrm{~mL})$ and extracted three times $(3 \times 5 \mathrm{~mL})$ with $117 \mathrm{CH}_{2} \mathrm{Cl}_{2}$. The aqueous phase was evapored under vacuum .

118 For the anion exchange step, the ammonium iodide $(25 \mathrm{mmol})$ was dissolved in water $(35 \mathrm{~mL})$ 119 and an aqueous saturated solution of lithium bis(trifluoromethanesulfonyl)imide (7.2 g, $25 \mathrm{mmol})$ 
120 was added. The liquid obtained was centrifuged and the ionic liquid and water were separated.

121 The ionic liquid was washed with water $(3 \mathrm{x} 10 \mathrm{ml})$ and finally vacuum-dried.

\subsection{Characterization of chiral ionic liquids}

124

The structures of the chiral ionic liquids were characterized by ${ }^{1} \mathrm{H},{ }^{13} \mathrm{C}$ and ${ }^{19} \mathrm{~F}$ NMR spectroscopy :

(R)(-) 1-hydroxy-N,N,N-trimethylbutan-2-aminium bis(trifluoromethanesulfonyl)imide (EtChol $\left.128 \mathrm{NTf}_{2}\right)$.

129 Colorless oil, ${ }^{1} \mathrm{H}$ NMR (400 MHz, MeOD) CD 3 CN/TMS $\delta(\mathrm{ppm}): 0.97\left(\mathrm{t},{ }^{3} \mathrm{~J}_{\mathrm{HH}}=7 \mathrm{~Hz}, 3 \mathrm{H}\right.$, $130 \mathrm{CH}_{3}-\mathrm{CH}_{2}$ ), 1.93 (quint, $\left.{ }^{3} \mathrm{~J}_{\mathrm{HH}}=2 \mathrm{~Hz}, 2 \mathrm{H}, \mathrm{CH}_{3}-\mathrm{CH}_{2}-\mathrm{CH}\right), 3.24$ (s, 10H, CH3-CH2-CH-(N131 (CH3)3)-CH2-OH), $3.73\left(\mathrm{dq},{ }^{3} \mathrm{~J}_{\mathrm{HH}}=14 \mathrm{~Hz},{ }^{4} \mathrm{~J}_{\mathrm{HH}}=4 \mathrm{~Hz}, 1 \mathrm{H}, \mathrm{CH}_{3}-\mathrm{CH}_{2}-\mathrm{CH}-\left(\mathrm{N}-\left(\mathrm{CH}_{3}\right)_{3}\right)-\right.$ $\left.132 \mathrm{CH}_{2}-\mathrm{OH}\right), 3,95\left(\mathrm{~d},{ }^{3} \mathrm{~J}_{\mathrm{HH}}=14 \mathrm{~Hz}, 1 \mathrm{H}, \mathrm{CH}_{3}-\mathrm{CH}_{2}-\mathrm{CH}-\left(\mathrm{N}-\left(\mathrm{CH}_{3}\right) 3\right)-\mathrm{CH}_{2}-\mathrm{OH}\right), 4.68\left(\mathrm{~s}, 1 \mathrm{H}, \mathrm{CH}_{3}-\right.$ $\left.133 \mathrm{CH} 2-\mathrm{CH}-\left(\mathrm{N}-\left(\mathrm{CH}_{3}\right) 3\right)-\mathrm{CH}_{2}-\mathrm{OH}\right) ;{ }^{13} \mathrm{C}$ NMR (62.9 MHz, MeOD) CD3CN/TMS $\delta(\mathrm{ppm}): 11.93$ 134 (s, 1C, $\mathrm{CH}_{3}$ ), 19.38 (s, 1C, $\left.\mathrm{CH}_{3}-\mathrm{CH}_{2}-\mathrm{CH}\right), 53.55$ (s, 3C, N-(CH3)3), 58.36 (s, 1C, CH- $\mathrm{CH}_{2}-$ $135 \mathrm{OH}), 78.77\left(\mathrm{~s}, 1 \mathrm{C}, \mathrm{CH}_{3}-\mathrm{CH}_{2}-\mathrm{CH}-\left(\mathrm{N}-\left(\mathrm{CH}_{3}\right) 3\right)-\mathrm{CH} 2-\mathrm{OH}\right), 121.60\left(\right.$ quad, ${ }^{1} \mathrm{~J} \mathrm{CF}=1273 \mathrm{~Hz}, 2 \mathrm{C}, \mathrm{N}-$

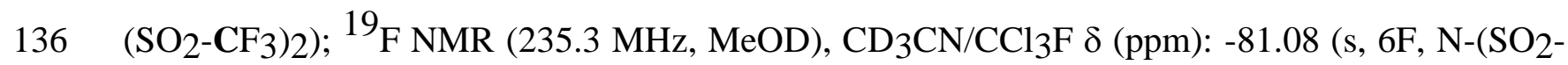
$\left.\left.137 \mathrm{CF}_{3}\right)_{2}\right)$

$(R)(-) \quad 2-h y d r o x y-N, N, N$-trimethyl-1-phenylethanaminium bis(trifluoromethanesulfonyl)imide 140 (PhChol NTf2).

141 Colorless oil, ${ }^{1} \mathrm{H}$ NMR (400 MHz, MeOD) CD 3 CN/TMS $\delta$ (ppm): 2.79 (s, 1H, OH), 3.19 (s, 9H, $\left.142 \mathrm{Ph}-\mathrm{CH}-\left(\mathrm{N}-\left(\mathrm{CH}_{3}\right) 3\right)-\mathrm{CH}_{2}-\mathrm{OH}\right), 4.22\left(\mathrm{~d},{ }^{3} \mathrm{~J}_{\mathrm{HH}}=13 \mathrm{~Hz}, 1 \mathrm{H}, \mathrm{Ph}-\mathrm{CH}-\left(\mathrm{N}-\left(\mathrm{CH}_{3}\right) 3\right)-\mathrm{CH}_{2}-\mathrm{OH}\right), 4.45$ $143\left(\mathrm{dd},{ }^{3} \mathrm{~J} \mathrm{HH}=13 \mathrm{~Hz},{ }^{3} \mathrm{~J}_{\mathrm{HH}}=7 \mathrm{~Hz}, 1 \mathrm{H}, \mathrm{Ph}-\mathrm{CH}-\left(\mathrm{N}-\left(\mathrm{CH}_{3}\right) 3\right)-\mathrm{CH}_{2}-\mathrm{OH}\right), 4.61\left(\mathrm{dd},{ }^{3} \mathrm{~J} \mathrm{HH}=7 \mathrm{~Hz}\right.$, $\left.1443^{3} \mathrm{JHH}_{\mathrm{HH}}=4 \mathrm{~Hz}, \mathrm{Ph}-\mathrm{CH}-\left(\mathrm{N}-\left(\mathrm{CH}_{3}\right) 3\right)-\mathrm{CH}_{2}-\mathrm{OH}\right), 7.49$ to $7.56(\mathrm{~m}, 3 \mathrm{C}, 1 \mathrm{H}$ para and $2 \mathrm{H}$ ortho), 7.62 145 to 7.65 (m, 2H, 2H meta); ${ }^{13} \mathrm{C} \mathrm{NMR} \mathrm{(62.9} \mathrm{MHz,} \mathrm{MeOD)} \mathrm{CD3CN/TMS} \delta(\mathrm{ppm}): 53.90$ (s, 3C, $\left.146 \mathrm{Ph}-\mathrm{CH}-\left(\mathrm{N}-\left(\mathrm{CH}_{3}\right)_{3}\right)-\mathrm{CH}_{2}-\mathrm{OH}\right) .62 .04$ (s, 1C, Ph-CH-(N-(CH3)3)-CH2-OH), 80.35 (s, 1C, Ph$\left.147 \mathrm{CH}-\left(\mathrm{N}-\left(\mathrm{CH}_{3}\right) 3\right)-\mathrm{CH}_{2}-\mathrm{OH}\right), 121.64\left(\mathrm{q},{ }^{1} \mathrm{~J}_{\mathrm{CF}}=1273 \mathrm{~Hz}, 2 \mathrm{C}, \mathrm{N}-\left(\mathrm{SO}_{2}-\mathrm{CF}_{3}\right) 2\right), 130.88(\mathrm{~s}, 3 \mathrm{C}, 1 \mathrm{C}$ 148 para , 2C meta), 132.35 (s, 2C, 2C ortho), 132.91 (s, 1C, C); ${ }^{19} \mathrm{~F}$ NMR (235.3 MHz, MeOD), $149 \mathrm{CD}_{3} \mathrm{CN} / \mathrm{CCl}_{3} \mathrm{~F} \delta(\mathrm{ppm})$ : -81.06 (s, 6F, N-( $\left.\mathrm{SO}_{2}-\mathrm{CF}_{3}\right)_{2}$.

150 
All experiments were performed with a $\mathrm{HP}^{3 \mathrm{D}} \mathrm{CE}$ (Agilent Technologies, Waldbronn,

153 Germany) capillary electrophoresis system. This apparatus automatically realized all the steps of 154 the measurement protocols, including capillary conditioning, sample introduction, voltage 155 application and diode array detection, and allows to run unattended method sequences. A CE

156 Chemstation (Agilent Technologies, Waldbronn, Germany) was used for instrument control, data 157 acquisition and data handling. Polymicro bare fused-silica capillaries of $50 \mu \mathrm{m}$ i.d. were obtained 158 from Photonlines (Marly-le-Roi, France). They were used in $35 \mathrm{~cm}$ total length $(26.5 \mathrm{~cm}$ to 159 detection). Background electrolytes (BGE) were made up with acetic acid/sodium acetate at two 160 different concentrations (5 and $60 \mathrm{mM}$ ) to a ${ }^{w_{w p}} \mathrm{pH}$ of 5.0. The methanol-water mixtures were 161 prepared by volumic mixing in 0,10 and $25 \%$ methanol proportions. Analytes were detected by 162 UV absorbance at 200, 230, 240, 254 and 300 nm, according to cases. Formamide $(0.001 \%$ (v/v) 163 in the BGE) was used as neutral marker to determine the electroosmotic mobility. The sample solutions were prepared by dissolving each analyte at a concentration of ca $0.5 \mathrm{mM}$ in methanol. 165 Samples were introduced hydrodynamically by successively applying a $30 \mathrm{mbar}$ pressure for $3 \mathrm{~s}$ 166 (approximately, $4 \mathrm{~nL}$ ) to the neutral marker, BGE and sample vials. New capillaries were conditioned by successive flushes with $1 \mathrm{M}$ and $0.1 \mathrm{M} \mathrm{NaOH}$ and then with water under a 168 pressure of $935 \mathrm{mbar}$ for $10 \mathrm{~min}$ each. The temperature in the capillary cartridge was set at $25^{\circ} \mathrm{C}$. 169 The acquisition rate was 10 points / $\mathrm{s}$. Capillaries were rinsed with water and dried by air when not in use.

\subsection{Capillary coating}

173 Capillaries were dynamically coated with polybrene as described in the literature [45-47].

174 Briefly, a new fused-silica capillary was first flushed with $1 \mathrm{M} \mathrm{NaOH}$ for $20 \mathrm{~min}$ and rinsed with 175 water. Next, the capillary was flushed with a polybrene solution at $3 \mathrm{~g} / 100 \mathrm{~mL}$ in water for 15 $176 \mathrm{~min}$. Finally, the capillary was rinsed with water for $5 \mathrm{~min}$ and conditioned with BGE for $5 \mathrm{~min}$, 177 all these steps being performed under a pressure of 935 mbar. Recoating of the capillary with the 178 cationic polymer was accomplished by using a similar method.

\subsection{Complexation constant determination}


182 The apparent formation constant $\mathrm{K}$ for the inclusion complexes between chiral PhChol cations

183 and neutral CDs of interest, was determined by mobility shift affinity capillary electrophoresis

184 (ACE) according to a method similar to that developed for a series of imidazolium based ILs

185 cations [48].

186

187 Briefly, PhChol $\mathrm{NTf}_{2}$ was dissolved at a concentration of $2 \mathrm{mM}$ and electrophoresed in BGEs

188 (ionic strength: $5 \mathrm{mM}$ ) containing increasing concentrations of DM- $\beta$-CD or TM- $\beta$-CD (0 to 100

$189 \mathrm{mM})$. Each injection with a given electrolyte was repeated twice. Effective mobilities $\left(\mu_{\mathrm{ep}}\right)$ of

190 PhChol cation were calculated from migration time measurement at peak apex. The obtained

191 values were corrected to compensate for change in electrolyte viscosity due to increasing CD

192 concentrations. The corrected values $\mu_{\text {ep,coor }}$ were fitted to non-linear and linear forms (linearized

193 isotherm, x-reciprocal, y-reciprocal, double reciprocal) of the 1:1 stoichiometry complexation

194 isotherm $[49,50]$ to determine the $\mathrm{K}$ value.

195

196

\subsection{Calculation of the performance parameters for the chiral separations}

197 The effective electrophoretic selectivity [51], $\alpha_{\mathrm{eff}}$, was calculated according to Eq. 1:

$$
\alpha_{e f f}=\frac{\mu_{e p 1}}{\mu_{e p 2}}
$$

where $\mu_{\mathrm{ep} 1}, \mu_{\mathrm{ep} 2}$ are the effective mobilities for enantiomers 1 and 2 .

The chiral resolution, $\mathrm{R}_{\mathrm{s}}$, between two enantiomers, 1 and 2, was calculated according to:

$$
R_{s}=1.177 \frac{t_{2}-t_{1}}{\delta_{1}+\delta_{2}}
$$

where $t_{1}, t_{2}$ are the migration times and $\delta_{1}, \delta_{2}$ are the temporal peak widths at half height.

\section{Results and discussion}

207 In a previous work, interactions between an achiral IL (1-butyl-3-methylimidazolium 208 bis(trifluoromethylsulfonyl)imide) and a series of 2-arylpropionic acids were studied in non 209 aqueous capillary electrophoresis (NACE) [43]. The results indicated a quadratic effect of the 
210 concentration of the achiral IL in the BGE on profen electrophoretic mobilities due to 211 antagonistic interactions between anionic analytes and imidazolium cations either adsorbed to the 212 capillary wall or free in the BGE electrolyte. With a view to evaluate a new family of chiral 213 selectors, the same conditions have been investigated with two chiral choline-based ILs (ethyl214 and phenylcholine bis(trifluoromethylsulfonyl)imide). No enantioselectivity has been shown in 215 these conditions for this family of compounds. This work was then directed to the study of the 216 association of a chiral IL to the best chiral selectors, reported previously for the 217 enantiorecognition of profens, DM- $\beta-C D$ and TM- $\beta-C D$ [52,53], to search for possible 218 synergistic effects. The use of CDs nevertheless is poorly compatible with that of nonaqueous 219 BGEs, to preserve adequate CD solubilization and partial formation of inclusion complexes. This 220 study was therefore realized in water and 90:10 and 75:25 (v/v) water-MeOH mixtures. The 221 choice of $\mathrm{MeOH}$ as molecular solvent in hydro-organic mixtures was based on its favorable 222 anion-solvating properties and ion-pairing and its ability to dissolve the tested CD.

223 The aim of this work was then to determine if a synergistic effect may exist between the chiral IL 224 cation and the $\mathrm{CD}$, and possibly to elucidate the interaction system bringing into play the three 225 different entities: analyte, chiral IL and $\beta-\mathrm{CD}$ derivative (Figure 2). The main parameters 226 expected to impact this complex system were the nature and concentration of the IL, the nature 227 and concentration of the $\mathrm{CD}$, the concentration of the buffer and the hydro-organic composition 228 of the BGE. The influence of adding LiNTf $_{2}$ to the separation electrolyte in place of the chiral ILs 229 was tested under the same conditions to discriminate specific chiral cation effect from a mere salt 230 effect. Also, the study was conducted either with bare fused silica capillaries or polybrene-coated 231 capillaries, to assess the influence of IL cation adsorbed to the capillary wall.

232 Owing to the number of parameters to be studied, only three model profens (naproxen, carprofen 233 and suprofen (Figure 1)) were investigated for the part of the experiments realized with bare 234 silica capillaries. For the experiments performed with polybrene-coated capillaries, which were 235 only realized in aqueous media, the following six profens were selected: naproxen, carprofen, 236 suprofen, ketoprofen, indoprofen and ibuprofen (Figure 1). The retained parameters for 237 discussion were effective electrophoretic chiral selectivity, $\alpha_{\mathrm{eff}}$, (thermodynamic parameter, 238 independent of electroosmotic flow variation) and chiral resolution, $\mathbf{R}_{\mathrm{s}}$, (global parameter). It is 239 to note that no enantioselectivity was obtained for naproxen under all conditions tested and for 240 suprofen under all DM- $\beta$-CD conditions. The results obtained for carprofen and suprofen with 
241 bare silica capillaries are given in Table 1, while those obtained for the five profens showing 242 enantioselectivity with polybrene-coated capillaries are presented in Table 2.

243 In a number of cases, an increase in resolution $R_{s}$ and a decrease in selectivity $\alpha_{\text {eff }}$ were observed

244 for the experiments with chiral ILs, as compared to the experiments without salt, but no general 245 trend on the evolution of $\mathrm{R}_{\mathrm{s}}$ and $\alpha_{\mathrm{eff}}$ can be traced.

Influence of electroosmotic flow and total salt concentration on $R_{s}$

249 The two chiral choline IL derivatives, EtChol and PhChol, were used in this work at a 250 concentration of $10 \mathrm{mM}$ and at two buffer salt concentrations (5 mM and $60 \mathrm{mM})$, in keeping 251 with the preliminary study realized with achiral imidazolium-based IL cation by NACE [38].

252 Indeed, the chiral IL addition in solution caused a change of system properties such as a possible 253 variation of the electrolyte viscosity, a marked increase in the total salt concentration, especially 254 when the buffer salt concentration is $5 \mathrm{mM}$, and a modification of the capillary wall. These three 255 parameters could mask a specific effect of the chiral IL on the enantiomeric separation.

256 The viscosity of each solution was measured using CE instrumentation by the method described 257 in the literature [54]. The results showed no difference upon adding an $\mathrm{IL}_{\text {or }} \mathrm{LiNTf}_{2}$ salt to a 258 solution already containing a CD. So, there was no viscosity effect due to the IL addition on 259 enantiomeric separation.

260 As the addition of the chiral IL was changing the total salt concentration of the solution, the same 261 experiments were realized with $\mathrm{LiNTf}_{2}$ salt in place of chiral IL to discriminate between a mere 262 salt effect and a specific effect due to the chiral nature of IL cations.

263 In effect, in a lot of cases, Table 1 shows an increase in $\mathrm{R}_{\mathrm{s}}$ upon chiral IL addition, but also upon $264 \operatorname{LiNTf}_{2}$ addition. Salt addition caused a decrease in electroosmotic mobility $\left(\mu_{\mathrm{eo}}\right)$ and under these 265 counter-electroosmotic flow condition an increase in $R_{s}$ values [55]. As expected, a more 266 important $\mu_{\mathrm{eo}}$ variation and hence $\mathrm{R}_{\mathrm{s}}$ increase was observed at the lower starting level of buffer 267 salt concentration $(5 \mathrm{mM})$, for which the relative variation in concentration was higher (Figure 3). 268 It was also noted that, with bare silica capillaries, in the majority of cases the addition of a chiral 269 IL caused a more important decrease in $\mu_{\mathrm{eo}}$ than $\mathrm{LiNTf}_{2}$ did. This decrease was likely due to the 270 adsorption of the IL cation to the capillary wall, as already mentioned by Stalcup [27,28]. To 271 further discriminate between IL cation wall adsorption and salt effect, the same experiments were 
272 resumed with polybrene-coated capillaries which are anticipated to eliminate the IL cation 273 interaction with capillary wall. Table 2 shows that in a majority of cases, an increase in $R_{s}$ for the 274 experiments with chiral IL and $\mathrm{LiNTf}_{2}$ was still observed as compared to CD-alone experiments. 275 In all these cases, a decrease in $\mu_{\text {eo }}$ was also observed, due to the increase in salt concentration.

276 These experiments with positively charged capillaries highlighted the significance of salt effects 277 on the chiral resolution of the five model profens.

\section{Influence of chiral IL on $\alpha_{e f f}$}

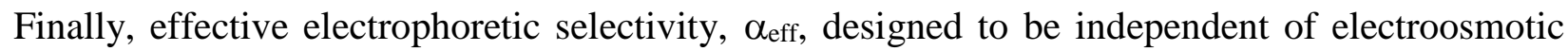
mobility, was the only parameter able to indicate a possible synergistic effect between the two selectors. In some cases, when the initial buffer salt concentration was $5 \mathrm{mM}$, an increase in $\alpha_{\text {eff }}$ was observed upon adding $10 \mathrm{mM}$ LiNTf $_{2}$ salt. This behavior can only be understood in considering that the apparent inclusion constants for profens into the CDs, which control $\alpha_{\text {eff, }}$ can be depending on electrolyte ionic strength. Apart from this, an increase in $\alpha_{\text {eff, }}$ with a difference of more than $3 \%$, in the presence of a chiral IL additive as compared to the experiments with the same concentration of LiNTf $_{2}$ was noted in five cases with bare silica capillaries (Table 1) and in four cases with the polybrene-coated capillaries (Table 2). Such a relative difference was considered as the limit of significance based on a mean $3 \%$ error for experimental electrophoretic values of chiral compounds (Table 1 and Table 2). Among these nine cases, eight were obtained with $5 \mathrm{mM}$ buffer salt concentration and all five cases identified in the experiments reported in

293 Table 1 were obtained with aqueous and hydroorganic media. It is to note that the experiments 294 with polybrene-coated capillaries were performed with both $5 \mathrm{mM}$ (results shown in Table 2) and $60 \mathrm{mM}$ (results not shown) buffer salt concentrations, but no case of synergy was observed at the higher concentration. In spite of the lack of general trend, this behavior suggests that the synergistic effect observed between the two selectors may be due to specific ion-pairing

299 The presence of the phenyl group in the chiral choline cation did not appear to be of importance 300 in the observation of apparent synergistic effects, whereas most cases were observed with TM- $\beta$ -

301 CD. For a better understanding of the interactions brought into play and to assess a possible 302 competition between the analyte and the IL cation for inclusion complex formation with the CD, 
303 a study on possible inclusion complexation between chiral IL cation and $\beta$-CD derivatives was 304 undertaken. Concerning EtChol $\mathrm{NTf}_{2}$, a recent study realized by our group on inclusion constant 305 determination between quite a large number of neutral CDs and alkyl(methyl)methylimidazolium 306 cations [48], revealed that the inclusion of IL cation almost exclusively depends on the alkyl 307 chain length. For 1-ethyl-3-methylimidazolium cation, no inclusion was measured with any 308 tested CD. On analogy, it seems reasonable to conclude that there is no inclusion between EtChol

309 cation and the two $\beta$-CD derivatives of the present study. The previously used mobility shift 310 affinity $\mathrm{CE}$ method was adapted to determine the apparent inclusion constant for PhChol cation 311 and DM- and TM- $\beta-C D$ in a acetic acid/sodium acetate buffer at $\mathrm{pH} 5.0$ (ionic strength, $30 \mathrm{mM}$ ) .

312 The results obtained in this work showed that there was no inclusion of PhChol cation into TM$313 \beta$-CD cavity but that this cation formed a complex with DM- $\beta-C D$ having an apparent constant of $314144 \pm 3$ at $25^{\circ} \mathrm{C}$. This difference in behavior could be explained by the more important steric 315 hindrance of TM- $\beta-C D$ as compared to DM- $\beta-C D$.

316 Eventually, the study of inclusion phenomena between chiral IL cations and used CDs showed 317 that there was an influence of the CD nature on the competition between the analyte and the IL 318 cation with the $\mathrm{CD}$. Nevertheless, the two thirds of apparent synergistic cases were observed with 319 TM- $\beta$-CD with respect to DM- $\beta$-CD for EtChol as well as PhChol ILs, which does not allow to 320 further clarify which factor is the most influent. 


\section{Conclusion}

325 This work focused on the evaluation of two chiral ILs (ethyl- and phenylcholine of 326 bis(trifluoromethylsulfonyl)imide) by CE. No direct enantioselectivity was observed for these

327 two chiral IL cations with respect to a series of arylpropionic acids, selected as model 328 compounds, in various nonaqueous BGE conditions. BGEs containing both a chiral IL cation and 329 a classical chiral selector (di- or trimethyl- $\beta$-cyclodextrin) in water and water-MeOH mixtures 330 were subsequently investigated to look for a compromise between the selective formation of 331 inclusion complexes, favored in aqueous electrolyte, and of ion-pairs, favored in nonaqueous 332 media. In most cases, an increase in resolution was observed upon adding one of the chiral IL, 333 but this variation was most often due to a decrease in electroosmotic flow, resulting from the 334 increase in salt concentration and a possible wall adsorption. In nine cases, however, 335 simultaneous increase in $\alpha_{\text {eff }}$ and Rs was observed as compared to a simple salt effect, which 336 suggests a synergistic effect of the two selectors. Apparent inclusion constant for EtChol and 337 PhChol cations and the used cyclodextrins were evaluated, demonstrating an influence of the CD 338 nature on the competition between the analyte and the IL cation with respect to CD 339 complexation. Nevertheless, the presence of the phenyl group in the IL cation appeared to be of 340 less importance in promoting these synergistic effects than that of methanol and of a low salt 341 concentration in the BGE, which suggests that specific ion-pairing interactions may be involved.

\section{Acknowledgements}

347 The authors thank Julie du Mazaubrun and Estelle Davesne for their collaboration in this work, 348 Jean-Marc Busnel and Thomas Le Saux for very fruitful discussions. 


\section{References}

353 [1]E. Gassmann, J.E. Kuo, R.W. Zare, Science 230 (1985) 813

354 [2] S. Fanali, J. Chromatogr. 494 (1989) 441

355 [3] B. Chankvetadze, Capillary Electrophoresis in Chiral Separation, Wiley and Sons, Chichester, 1997.

356 [4] M.I. Jimidar, W. Van Ael, P. Van Nyen, M. Peeters, D. Redlich, M. De Smet, Electrophoresis 25 (2004) 2772.

357 [5] B. Chankvetadze, G. Blaschke, J. Chromatogr. A 906 (2001) 309.

358 [6] H. Nishi, S. Terabe, J. Chromatogr. A 875 (2000) 1.

359 [7] G. Vigh, A.D. Sokolowski, Electrophoresis 18 (1997) 2305.

360 [8] G. Gübitz, M.G. Schmid, Electrophoresis 25 (2004) 3981.

361 [9] M. Lämmerhofer, J. Chromatogr. A 1068 (2005) 3

362 [10] M. Lämmerhofer, J. Chromatogr. A 1068 (2005) 31

363 [11] A. Van Eeckhaut, Y. Michotte, Electrophoresis 27 (2006), 2880.

364 [12] P. Wasserscheidt, T. Weldon, Ionic Liquids in Synthesis, Wiley-VCH, New-York, 2003.

365 [13] J. Dupont, R.F. de Souza, P.A.Z. Suarez, Chem. Rev. 102 (2002) 3667.

366 [14] P. Wasserscheidt, W. Keim, Angewandte Chem. Int. Ed. 39 (2000) 3772.

367 [15] M.J. Earle, K.R. Seddon, Pure Appl. Chem. 72 (2000) 1391.

368 [16] S.G. Cull, J.D. Holbrey, V. Vargas-Mora, K.R. Seddon, G.J. Lye, Biotechnol. Bioeng. 69 (2000) 227.

369 [17] J.G. Huddleston, H.D. Willauer, R.P. Swatloski, A.E. Visser, R.D. Rogers, Chem. Comm. (1998) 1765.

370 [18] A.G. Fadeev, M.M. Meagher, Chem. Comm. (2001) 295.

371 [19] A.E. Visser, R.P. Swatloski, R.D. Rogers, Green Chem. 2 (2000) 1.

372 [20] F. Pachole, H.T. Butler, C.F. Poole, Anal. Chem. 54 (1982) 1938.

373 [21] D.W. Armstrong, J.L. Andersen,J. Ding, T. Welton, J. Am. Chem. Soc. 124 (2002) 14247.

374 [22] A. Berthod, L. He, D.W. Armstrong, Chromatographia 53 (2001) 63.

375 [23] A. Heintz, D.W. Kulikov, S.P. Verevkin, J. Chem. Eng. Data 47 (2002) 894.

376 [24] M.J. Ruiz-Angel, S. Carda-Broch, A. Berthod, J. Chromatogr. A 1119 (2006) 202.

377 [25] M.P. Marszall, T. Baczek, R. Kaliszan, J. Sep. Sci. 29 (2006) 1138.

378 [26] X. Xiao, L. Zhao, X. Liu, S. Jiang, Anal. Chim. Acta 519 (2004) 207.

379 [27] E.G. Yanes, S.R. Gratz, A.M. Stalcup, The Analyst 125 (2000) 1919.

380 [28] E.G. Yanes, S.R. Gratz, M.J. Baldwin, S.E. Robinson, A.M. Stalcup, Anal. Chem. 73 (2001) 3838.

381 [29] M. Vaher, M. Koel, M. Kaljurand, Chromatographia 53 (2001) S-302.

382 [30] M. Vaher, M. Koel, M. Kaljurand, Electrophoresis 23 (2002) 426.

383 [31] M. Vaher, M. Koel, M. Kaljurand, J. Chromatogr. A 979 (2002) 27.

384 [32] R. Kuldvee, M. Vaher, M. Koel, M. Kaljurand, Electrophoresis 24 (2003) 1627.

385 [33] M. Vaher, M. Koel, J. Chromatogr. A 990 (2003) 225.

386 [34] K. Tian, S. Qi, Y. Cheng, X. Chen, Z. Hu, J. Chromatogr. A 1078 (2005) 181.

387 [35] S. Qi, Y. Li, Y. Deng, Y. Cheng, X. Chen, Z. Hu, J. Chromatogr. A 1109 (2006) 300. 
[36] M.P. Marszall, M.J. Markuszewski, R. Kaliszan, J. Pharm. Biomed. Anal. 41 (2006) 329.

389 [37] M.E. Yue, Y.P. Shi, J. Sep. Sci. 29 (2006) 272.

390 [38] S.M Mwongela, A. Numan, N.L. Gill, R.A. Agbaria, I.M. Warner, Anal. Chem. 75 (2003) 6089.

391 [39] J. Ding, D. W. Armstrong, Chirality 17 (2005) 281.

392 [40] C. Baudequin, D. Brégeon, J. Levillain, F. Guillen, J-C. Plaquenvent, A-C. Gaumont, Tetrahedron: Asymmetry

393 16, (2005) 3921.

394 [41] S.A.A. Rizvi, S.A. Shamsi, Anal. Chem. 78 (2006) 7061.

395 [42] B.K. Patel, M. Hanna-Brown, M.R. Hadley, A.J. Hutt, Electrophoresis 25 (2004) 2625.

396 [43] Y. Francois, A. Varenne, E. Juillerat, A-C. Servais, P. Chiap, P. Gareil, J. Chromatogr. A 1138 (2007) 268.

397 [44] P. Wasserscheid, A. Bosman, C. Bolm, Chem. Commun. (2002) 200.

398 [45] Y.J. Yao, S.F.Y. Li, J. Chromatogr. A 680 (1994) 431.

399 [46] E. Cordova, J. Gao, G.M. Whitesides, Anal. Chem. 69 (1997) 1337.

400 [47] A. Macia, F. Borrull, M. Calull, C. Aguilar, Electrophoresis 25 (2004) 3441.

401 [48] Y. Francois, A. Varenne, J. Sirieix, P. Gareil, J. Sep. Sci. in press.

402 [49] K.A. Connors, Binding Constants. The Measurements of Molecular Complex Stability. John Wiley \& Sons, 403 New York, 1987

404 [50] K.L. Rundlett, D.W. Armstrong, J. Chromatogr. A 721 (1996) 173.

405 [51] F. Lelièvre, P. Gareil, A. Jardy, Anal. Chem. 69 (1997) 385.

406 [52] S. Fanali, Z. Aturki, J. Chromatogr. A 694 (1995) 297.

407 [53] F. Lelièvre, P. Gareil, J. Chromatogr. A 735 (1996) 311.

408 [54] Y. Francois, K. Zhang, A. Varenne, P. Gareil, Anal. Chim. Acta 562 (2006) 164.

409 [55] C. Schwer, E. Kenndler, Chromatographia 33 (1992) 331

410

411

412

413

414

415

416

417 


\section{Captions}

419

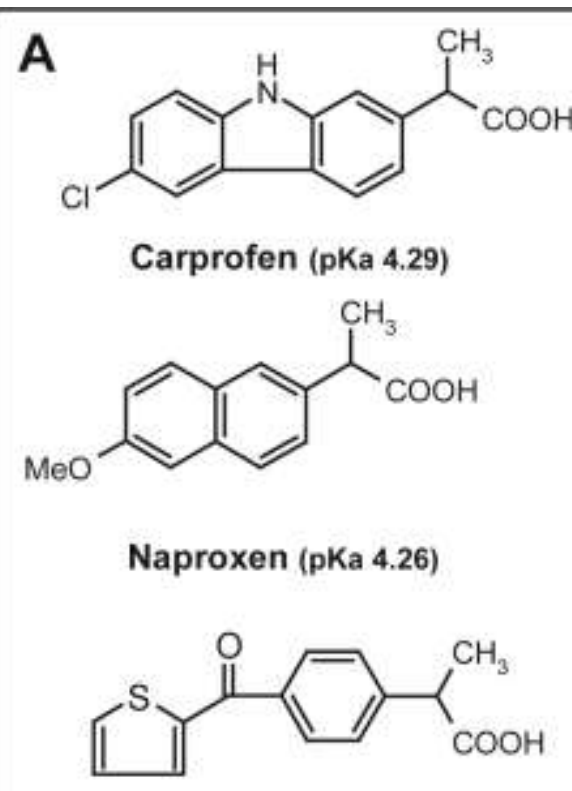

Suprofen (pKa 4.00)<smiles>CC(C(=O)O)c1cccc(C(=O)c2ccccc2)c1</smiles>

Ketoprofen (pKa 4.03)<smiles>CC(C(=O)O)c1ccc(N2Cc3ccccc3C2=O)cc1</smiles>

Indoprofen (pKa 4.29)

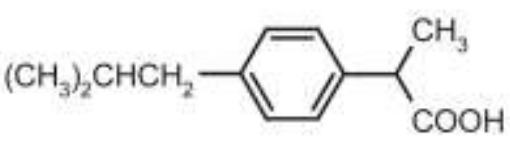

Ibuprofen (pKa 4.41)
B<smiles>C[N+](C)(C)[C+](CO)c1ccccc1</smiles><smiles>CC[C](CO)[N+](C)(C)C</smiles>

$\mathrm{PhChol}^{+}$

EtChol $^{+}$<smiles>O=S(=O)(NS(=O)(=O)C(F)(F)F)C(F)(F)F</smiles>

Bis(trifluorometylsulfonyl) imide $\mathrm{NTf}_{2}^{-}$

421 Figure 1: Structures of (A) the studied arylpropionic acids and (B) ionic liquids ethylcholine and 422 phenylcholine bis(trifluoromethanesulfonyl)imide $\left(\right.$ EtCholNTf $_{2}$, PhCholNTf $\left._{2}\right) \cdot \mathrm{pK}_{\mathrm{a}}$ values at 26$423 \quad 27^{\circ} \mathrm{C}$ from [53] 


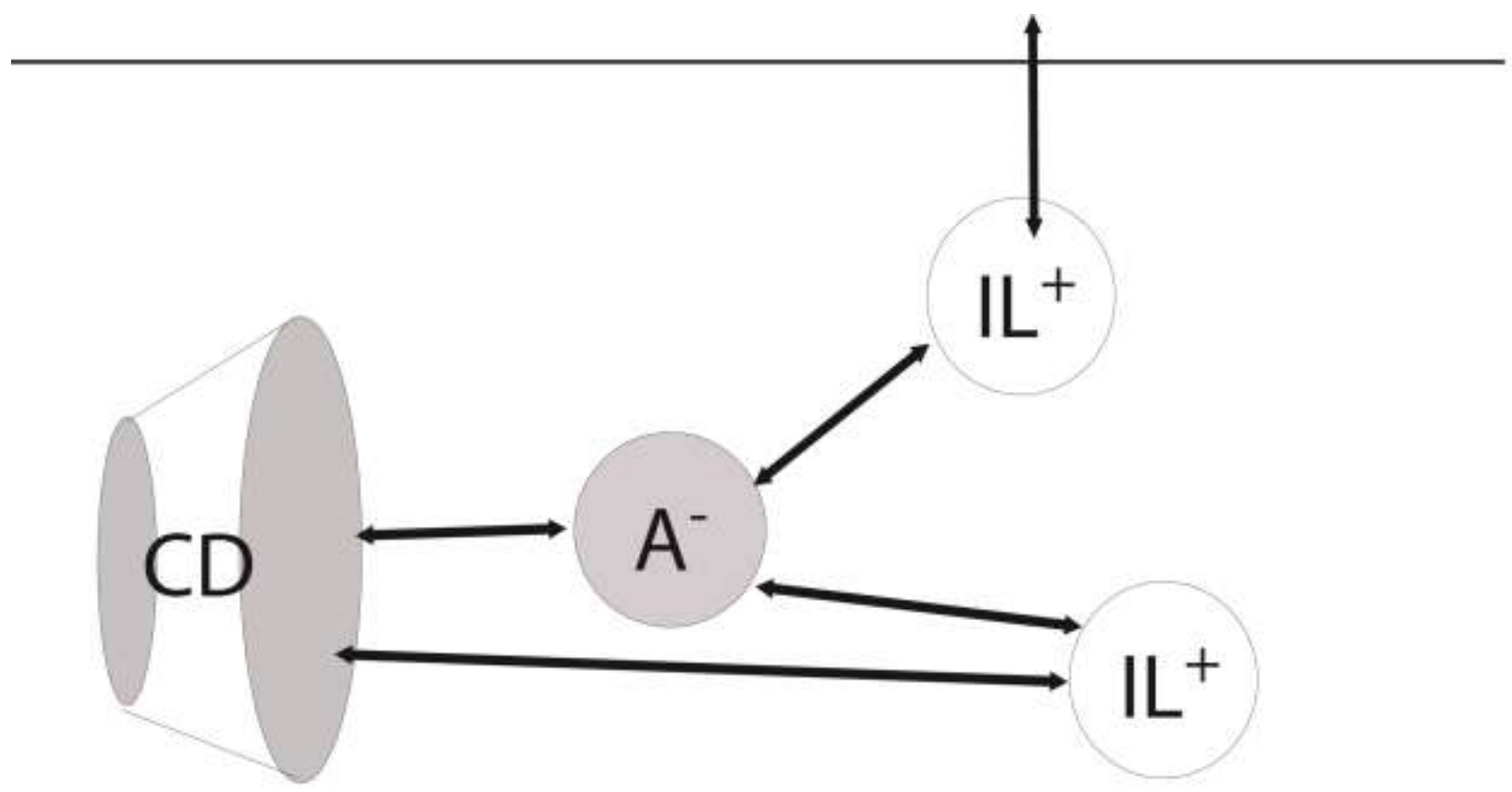

426 Figure 2: Schematic description of the interaction system between anionic profen, chiral IL 427 cation, free in the BGE or adsorbed onto the capillary wall, and $\beta$-CD derivatives.

428

429 


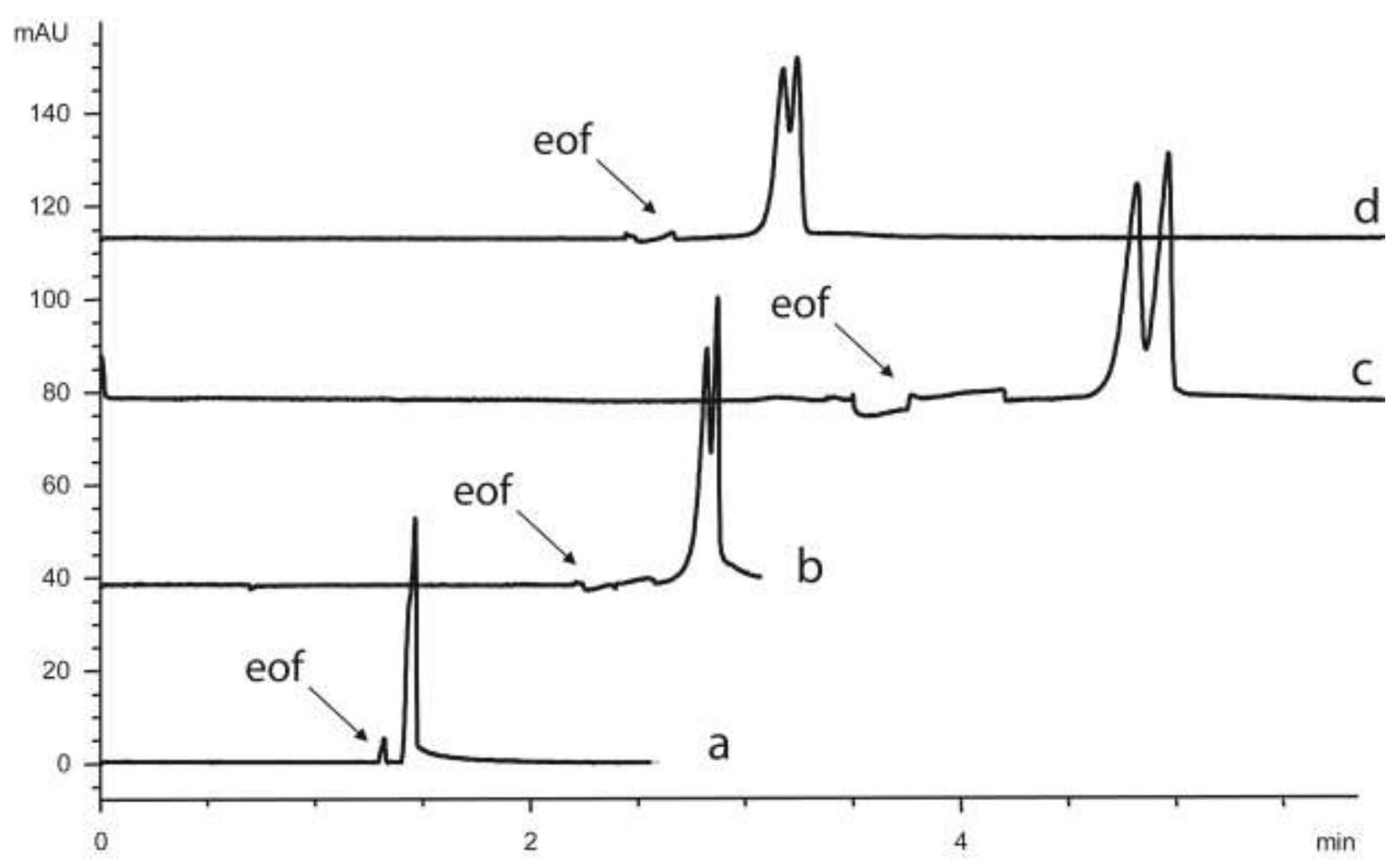

431 Figure 3: Enantioseparation of carprofen in the presence of TM- $\beta$-CD and chiral ILs.

432 Fused silica capillary, $50 \mu \mathrm{m}$ i.d. $35 \mathrm{~cm}$ (effective length, $26.5 \mathrm{~cm}$ ). Electrolyte: $2.63 \mathrm{mM}$ acetic 433 acid, $5.0 \mathrm{mM}$ sodium acetate buffer, ${ }^{\mathrm{w}}{ }_{\mathrm{w}} \mathrm{pH} 5.0$ containing (a) $30 \mathrm{mM}$ TM- $\beta-\mathrm{CD}$, (b) $30 \mathrm{mM}$ TM$434 \beta-\mathrm{CD}+10 \mathrm{mM}$ EtCholNTf $_{2}$, (c) $30 \mathrm{mM}$ TM- $\beta-\mathrm{CD}+10 \mathrm{mM}$ PhCholNTf $_{2}$ (d) $30 \mathrm{mM}$ TM- $\beta-\mathrm{CD}$ $435+10 \mathrm{mM} \mathrm{LiNTf}_{2}$ in (90:10, v/v) $\mathrm{H}_{2} \mathrm{O}-\mathrm{MeOH}$ mixture. Applied voltage: $25 \mathrm{kV}$. Temperature: 25 $436{ }^{\circ} \mathrm{C}$. UV absorbance at $230 \mathrm{~nm}$. Hydrodynamic injection (30 mbar, $3 \mathrm{~s}$ ). EOF: electroosmotic 437 flow. 